\title{
Chapter 9 \\ Diagnosis, Treatment, and Management of Hemophagocytic Lymphohistiocytosis in the Critical Care Unit
}

\author{
Melissa Hines, Neel Bhatt, and Julie-An M. Talano
}

\section{Introduction}

\section{Definitions, HLH Nomenclature, and Clinical Presentation}

Hemophagocytic lymphohistiocytosis (HLH) is a hyperinflammatory syndrome characterized by significant CD8 T-cell and macrophage activation and severe hypercytokinemia. This hypercytokinemia can lead to severe multi-organ dysfunction which often requires aggressive supportive care within the intensive care unit. Given the syndromic nature of the disease, HLH is defined by the constellation of certain physical exam findings and laboratory criteria that were initially defined by the Histiocyte Society in the HLH-94 protocol [1, 2] and then updated in the HLH-2004 protocol [3]. While these diagnostic criteria were initially intended as inclusion criteria for these protocols, they remain the most widespread and accepted clinical diagnostic criteria. In the initial HLH-94 definition, patients had to meet five of five diagnostic criteria to be included within the study, including fever, splenomegaly, hemophagocytosis, hypertriglyceridemia and/or hypofibrinogenemia, and cytopenias [1,2]. With the HLH-2004 protocol, the diagnostic criteria were updated to include elevated soluble IL-2 receptor, reduced or absent NK-cell cytotoxic function, and hyperferritinemia [3]. Patients were required to meet at least 5 of 8 criteria or harbor genetic defects known to cause HLH for inclusion in the study protocol (Table 9.1) [3].

\footnotetext{
M. Hines $(\bowtie)$

Department of Pediatric Medicine, Division of Critical Care, St. Jude Children's Research Hospital, Memphis, TN, USA

e-mail: Melissa.Hines@STJUDE.ORG

N. Bhatt · J.-A. M. Talano

Department of Pediatrics, Division of Pediatric Hematology/Oncology,

Medical College of Wisconsin, Children's Hospital of Wisconsin, Milwaukee, WI, USA
} 
Table 9.1 HLH

diagnostic criteria from HLH-2004 protocol

\begin{tabular}{l}
\hline Five of criteria below \\
Fever \\
\hline Splenomegaly \\
\hline Cytopenias (affecting $\geq 2$ of 3 lineages in the peripheral blood $)$ \\
\hline Hemoglobin $<9 \mathrm{~g} / \mathrm{dl}(10 \mathrm{~g} / \mathrm{dl}$ in infants less than 4 weeks $)$ \\
$\quad$ Platelets $<100 \times 10^{9} / \mathrm{L}$ \\
$\quad$ Neutrophils $<1 \times 10^{9} / \mathrm{L}$ \\
Hypertriglyceridemia and/or hypofibrinogenemia \\
$\quad$ Fasting triglycerides $\geq 265 \mathrm{mg} / \mathrm{dl}$ \\
\hline Fibrinogen $\leq 150 \mathrm{~g} / \mathrm{dl}$ \\
\hline Presence of hemophagocytosis in bone marrow or other tissue \\
\hline Low or absent NK-cell activity \\
Ferritin $\geq 500$ microgram/L \\
\hline Soluble IL-2 receptor $(\mathrm{CD} 25) \geq 2400 \mathrm{U} / \mathrm{ml}$
\end{tabular}

HLH is often differentiated into primary or familial HLH (fHLH) or secondary HLH (sHLH) based on whether a genetic defect associated with HLH can be identified. Those with a genetic defect are classified as having $\mathrm{fHLH}$, whereas those with secondary HLH are thought to have overwhelming immune system activation due to infection, malignancy, or another cause rather than disease caused by an underlying genetic defect. The pathophysiology and the current understanding about the differentiation of fHLH and sHLH is evolving as many secondary HLH patients are found to have other genetic changes that can predispose them to the development of HLH. This will be discussed in more detail in the HLH pathophysiology section. Regardless, experts typically use the HLH-2004 diagnostic criteria as a guide for diagnosis of both fHLH and sHLH. Macrophage activation syndrome (MAS) refers to the cytokine storm and inflammation that can be associated with rheumatologic disease. While MAS is often categorized as a form of secondary HLH, new diagnostic criteria have been formed in recent years to specifically define MAS associated with systemic juvenile idiopathic arthritis (sJIA; Table 9.2), but there are no currently diagnostic criteria for MAS associated with other rheumatologic diseases.

Fever $(91 \%)$ and splenomegaly $(84 \%)$ are two of the most common clinical features described in HLH [4]. Fever in HLH patients is particularly notable as it tends to be high and persistent despite antimicrobial therapy [5]. Primary HLH patients in particular have very prominent organomegaly (hepatomegaly and splenomegaly) that often progresses with time [5]. Cytopenias, especially thrombocytopenia (97\%) and anemia (88\%), are common laboratory findings [2]. Neutropenia is less common $(69 \%)$ at the time of diagnosis [2]. These patients can also have DIC with significant hypofibrinogenemia, but this finding is more variable (primary HLH 60-65\%; secondary HLH 40\%) [6]. When hypofibrinogenemia is present, it is highly suggestive of HLH and can be helpful in differentiating patients with HLH from patients with sepsis who tend to have DIC with hyperfibrinogenemia [5]. Elevated ferritin is a marker of inflammatory response and macrophage activation 
Table 9.2 Diagnostic criteria for macrophage activation syndrome in sJIA

\begin{tabular}{l}
\hline Suspected or confirmed diagnosis of sJIA \\
\hline Fever \\
\hline Ferritin $>684 \mathrm{ng} / \mathrm{ml}$ \\
\hline AND any two of the following: \\
\hline Platelet count $\leq 181 \times 10^{9} / \mathrm{L}$ \\
\hline Aspartate aminotransferase $>48 \mathrm{u} / \mathrm{L}$ \\
\hline Triglycerides $>156 \mathrm{mg} / \mathrm{dl}$ \\
\hline Fibrinogen $\leq 360 \mathrm{mg} / \mathrm{dl}$ \\
\hline
\end{tabular}

and is seen in up to $93 \%$ of HLH cases. Hyperferritinemia, particularly $>10,000 \mu \mathrm{g} / \mathrm{L}$, is a highly sensitive (90\%) and specific (96\%) test for HLH and can differentiate hyperferritinemia seen in other conditions such as liver disease, chronic transfusions, and infections [7]. Hypertriglyceridemia is common (80\%), but is not specific for HLH and thought to be secondary to elevated TNF-alpha levels [5, 8]. In addition to ferritin, elevated serum-soluble IL-2 receptor ( $\alpha$ chain; sCD25), a marker of T-cell activation, is helpful for diagnosis and disease monitoring [9]. Other HLH testing included in the HLH-2004 diagnostic criteria includes tissue or bone marrow biopsy with the presence of hemophagocytosis and NK-cell function. Decreased or absent NK-cell function is suggestive of HLH but can be normal in both primary and secondary HLH [10]. Similarly, the presence of hemophagocytosis can be suggestive of HLH if other clinical and laboratory criteria are met, but is not specific or necessary for the diagnosis of HLH [11].

There are several other important clinical and laboratory findings that are not part of the HLH-2004 diagnostic criteria which are often found in HLH patients. For example, liver dysfunction evident by elevated transaminases and bilirubin (typically direct hyperbilirubinemia) is a common associated finding [2, 5, 9]. Cases of fulminant liver failure and hydrops fetalis have been reported in patients who have ultimately been diagnosed with HLH [12]. Elevated AST, ALT, and bilirubin have been reported in $76 \%, 76 \%$, and $51 \%$ of the patients, respectively. Other common abnormal laboratory findings include elevated LDH, hyponatremia, and hypoalbuminemia [1-3, 8]. More variable clinical findings include edema, ascites, respiratory failure, lymphadenopathy, rash (30-65\%), and CNS involvement $[2,5,13]$. Symptoms concerning for CNS involvement include seizures, mental status changes, or focal neurologic findings and can be seen in up to $75 \%$ of the pediatric HLH cases $[2,4,13,14]$. In the HLH-94 study, patients with CNS HLH $(n=122)$ presented with either abnormal CSF studies (CSF pleocytosis, elevated protein; 41\%) or neurological symptoms (17\%) or both (42\%) [14]. MRI findings are just as broad as the neurologic symptoms in HLH and include leptomeningeal enhancement, hemorrhage, and T2 and FLAIR hyperattenuation $[15,16]$. Both MRI changes and CSF findings can be seen in patients that have no CNS symptomatology. Rare cases of isolated CNS HLH (i.e., no or few systemic HLH manifestations) have also been reported in the literature which makes the diagnosis challenging [17-19]. Skin manifestations such as rashes are present in up to $65 \%$ of the cases [9]. Types of rashes 
range from generalized maculopapular to petechiae and purpura [20]. These signs and symptoms can be seen in patients with or without an identifiable trigger, such as infection. In short, while the presentation of HLH is extremely variable, patients that raise suspicion for HLH include those who are persistently febrile with cytopenia and hepatosplenomegaly and are often critically ill with some evidence of liver dysfunction and/or DIC with hypofibrinogenemia.

\section{Incidence and Mortality}

The incidence of familial HLH has been estimated to be 1 in 50,000 live births with average survival of 2 months and a mortality of greater than $90 \%$ without therapy $[4,21]$. The estimated incidence of both primary and secondary HLH is not known but has been reported to be 1 in 3000 inpatient admissions in a retrospective review at a single center [7]. While mortality has significantly improved over the last 20 years, it remains high for both adult and pediatric HLH patients. Mortality in the adult population has been reported to be 22-59\% [22-24]. With the introduction of etoposide-based immunochemotherapy, pediatric HLH survival has improved from less than $10 \%$ to a 5 -year survival of $55 \%$ to $61 \%$ [1, 2, 25]. Familial HLH patients that receive a bone marrow transplant have a reported survival of $64 \%$ at 3 years and $58-66 \%$ at 5 years $[1,2,25,26]$.

\section{HLH Pathophysiology}

\section{Primary HLH}

The understanding of the pathophysiology of HLH has grown dramatically over the last 15 years with the discovery of loss-of-function germline mutations in the PRF1 gene, which encodes the protein perforin, in familial HLH patients [27-29]. Prior to this discovery, it was recognized that HLH patients often exhibited NK cytotoxic dysfunction, but the cause of the dysfunction was unknown [30, 31]. Since this initial discovery, several other genes have been identified to cause the HLH phenotype, many of these involving the sorting, trafficking, docking, and fusion of cytotoxic granules containing granzymes A and B and perforin to the cell membrane (including the proteins LYST, AP-3 complex, Rab27a, Munc 13-4, Munc 18-2, Syntaxin 11) $[9,32,33]$. In these cases, the cytotoxic granules do not contain perforin, or they are unable to stably dock and/or fuse with the cell membrane, preventing optimal perforin pore formation and granzymes A and B delivery to the target cell (Fig. 9.1). Typically, once the cytotoxic granule saddles up to the cell membrane and fuses, perforin proteins come together to form a pore-like structure allowing the release of granzymes A and B from the granule of the NK or cytotoxic T cell into the target cell. Once in the target cell, granzymes A and B stimulate the apoptosis cascade 


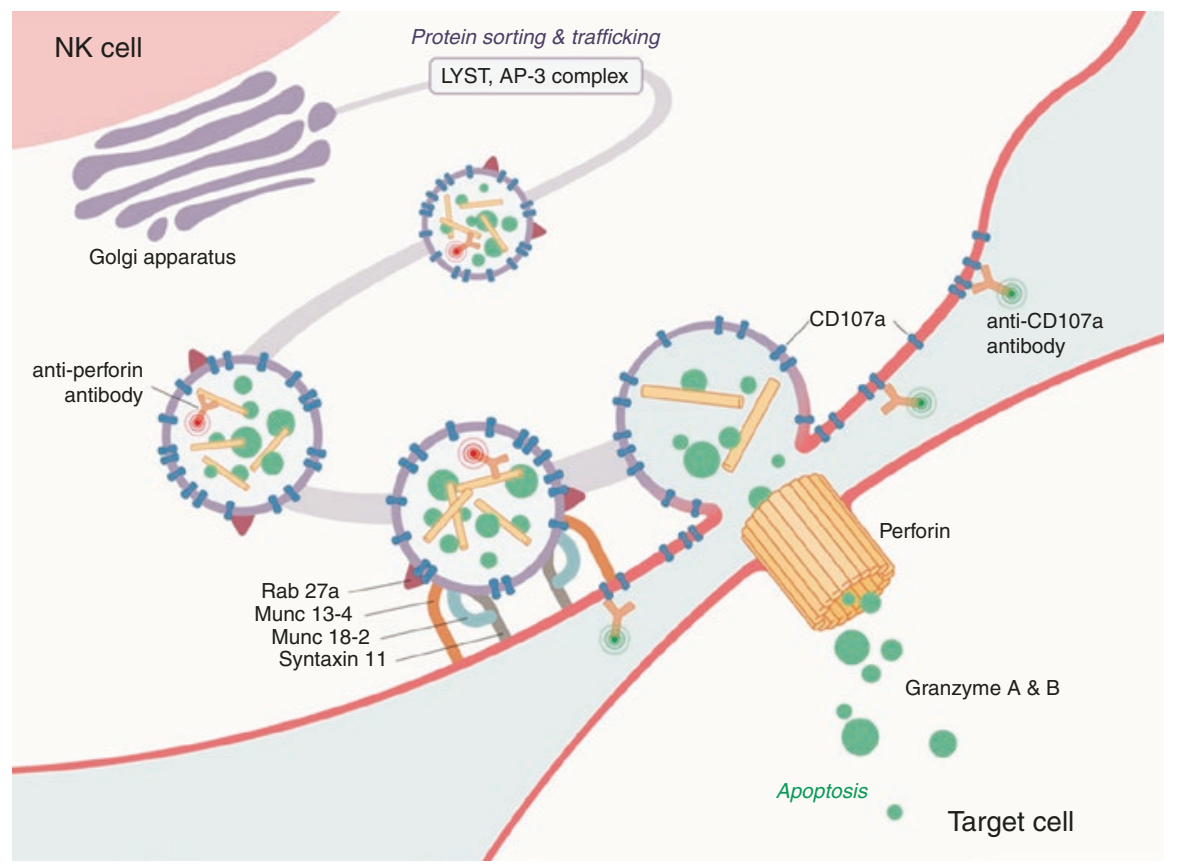

Fig. 9.1 Function of HLH-related proteins and cytotoxic cell function and the use of CD107a and perforin expression assays for diagnosis. LYST (function not fully understood) and AP-3 function in protein trafficking and sorting from the Golgi apparatus to the formation of the cytotoxic granules. As seen in the figure, granzymes A and B, as well as perforin, are packaged in the cytotoxic granules. Rab27a function is in cytotoxic vesicle trafficking and cytotoxic vesicle membrane fusion to the effector cell membrane. Munc 13-4, Munc 14-2, and Syntaxin 11 assist in the docking, priming, and fusion of the cytotoxic granule to the effector cell membrane for degranulation. Once the cytotoxic vesicle fuses with the effector cell membrane, individual perforin proteins come together to form a pore-like structure that allows granzymes packaged in the cytotoxic granules to pass from the effector cell to the target cell causing target cell death. CD107a is found within the membrane of the cytotoxic granule and is expressed in the cell membrane once the cytotoxic membrane fuses with the cell membrane during cytotoxic granule degranulation. Perforin and CD107a expression testing uses fluorescently conjugated anti-perforin and anti-CD107a antibodies and detects and quantifies the amount of florescence by flow cytometry. Perforin expression assay determines the amount of perforin within the cytotoxic vesicles within the cell. In CD107a expression testing, NK and cytotoxic T cells are stimulated to degranulate. After degranulation, anit-CD107a antibodies attach to CD107a expressed on the cell membrane (This figure was originally published in Blood. Hines and Nichols [34])

leading to cell death [35]. In the case of PFRl mutations (codes the perforin protein), the cytotoxic granule is appropriately trafficked and can fuse with the cell membrane, but there is a decreased or an absent perforin. Therefore, no perforin pore is made, and granzyme A or granzyme B is not delivered to the target cell to induce apoptosis $[32,33,36]$. These known gene mutations account for FHL 2-5 (PFR1, UNC13D, STX11, STXBP2) and three other immunodeficiency disorders, Griscelli syndrome type 2, Chediak-Higashi syndrome, and Hermansky-Pudlak 
Table 9.3 Genetic causes of HLH and associated tests

\begin{tabular}{|c|c|c|c|c|c|}
\hline Disease & $\begin{array}{l}\text { Gene } \\
\text { name }\end{array}$ & $\begin{array}{l}\text { Encoded } \\
\text { protein }\end{array}$ & $\begin{array}{l}\text { Perforin } \\
\text { expression }\end{array}$ & $\begin{array}{l}\text { CD107a } \\
\text { upregulation }\end{array}$ & $\begin{array}{l}\text { NK cell } \\
\text { cytotoxicity }\end{array}$ \\
\hline FHL2 & PRF1 & Perforin & $\downarrow \downarrow$ & Normal & $\downarrow$ or 0 \\
\hline FHL3 & $U N C 13 D$ & Munc13-4 & Normal & $\downarrow \downarrow$ & $\downarrow$ or 0 \\
\hline FHL4 & STX11 & Syntaxin 11 & Normal & $\downarrow \downarrow$ & $\downarrow$ or 0 \\
\hline FHL5 & $S T X B P 2$ & Munc18-2 & Normal & $\downarrow \downarrow$ & $\downarrow$ or 0 \\
\hline Griscelli & $R A B 27 A$ & Rab27a & Normal & $\downarrow \downarrow$ & $\downarrow$ or 0 \\
\hline $\begin{array}{l}\text { Chediak- } \\
\text { Higashi }\end{array}$ & $L Y S T$ & LYST & Normal & $\downarrow \downarrow$ & $\downarrow$ or 0 \\
\hline $\mathrm{XLP}^{\mathrm{a}}$ & $S H 2 D 1 A$ & $\mathrm{SAP}^{\mathrm{b}}$ & Normal $^{\mathrm{d}}$ & Normal $^{\text {d }}$ & $\downarrow$ or normal \\
\hline XLP2 & BIRC4 & XIAP $^{c}$ & Normal $^{\mathrm{e}}$ & Normal $^{\mathrm{e}}$ & $\downarrow$ or normal \\
\hline $\mathrm{HPS}^{\mathrm{f}}$ & $A P 3 B 1$ & AP3g & Normal & $\downarrow \downarrow$ & $\downarrow$ \\
\hline
\end{tabular}

${ }^{a} \mathrm{X}$-linked lymphoproliferative syndrome

${ }^{\mathrm{b}}$ signaling lymphocytic activation molecule (SLAM)-associated protein

${ }^{c} \mathrm{X}$-linked inhibitor of apoptosis

${ }^{\mathrm{d}} \mathrm{X} A \mathrm{P}$ expression decreased

'XIAP expression decreased

${ }^{f}$ Hermansky-Pudlak syndrome type 2

gadaptor protein 3 complex

This figure was originally published in Blood. Hines and Nichols [34]

syndrome type 2 (RAB27A, LYST, AP3B1; Table 9.3), which are all inherited in an autosomal recessive fashion $[9,32]$. In addition to these disorders, there are two $\mathrm{X}$-linked disorders that can lead to an HLH phenotype [3, 9, 32]. X-linked lymphoproliferative disease types 1 and 2 are caused by a defect in the genes SH2DIA and $B I R C 4$, which code for the SAP and XIAP proteins, respectively. SAP protein is thought to play a role in effector function of multiple immune cells including NK, NKT, and T cells by relaying proper signaling for the polarization of granules [32]. Due to the defect in effector function, there can be impaired NK and CD8 T-cell cytotoxic dysfunction that is thought to lead to the HLH phenotype, particularly after EBV infection [32, 37, 38]. XIAP is an anti-apoptotic protein that inhibits caspase activity, but how a defect in this protein leads to HLH pathophysiology is not as well understood [32].

How do these defects in cytotoxic function lead to a cytokine storm? Familial or primary HLH is an immunodeficiency as well as a hyperinflammatory syndrome. The effector function of NK and CD8 T cells kills cells with intracellular infection as well as cells that are dysfunctional, such as cancer cells. In addition to the surveillance function that these cells serve, they also play a crucial role in controlling the immune response by eliminating immune cells that are no longer needed, including antigen-presenting cells. Based on what we know from murine models, both CD8 T cells and interferon-gamma are imperative to the formation of the cytokine storm and clinical findings of primary HLH [39]. In an HLH flare, the initial immune response including immune activation is appropriate but is later complicated by persistent antigenemia, persistent antigen presentation, uncontrolled monoclonal expansion of CD8 T cells, and hypercytokinemia (predominately INF-gamma) [33, 39-41]. Once 
there is a triggering event, such as a viral infection, CD8 T cells are activated by antigen-presenting cells (APCs) and monoclonally expand both in the blood and in the tissue and secrete interferon-gamma. Interferon-gamma activates and then recruits macrophages to the area $[32,33]$. Macrophages in turn secrete multiple cytokines, including IL-18, IL-10, IL-6, IL-1beta, and TNF-alpha, which provide a feedback loop for further CD8 T-cell activation and proliferation [32, 39, 42]. This process of CD8 T-cell activation continues, since virally infected cells cannot be eliminated due to defective degranulation of CD8 T cells and NK cells, leading to persistent antigenemia and cytokine production [33, 40, 43]. APCs are typically removed by NK and CD8 T cells but remain in this case due to the ineffective cytotoxic function of these cells $[33,40,41]$. Continued activation and expansion of the CD8 T cells lead to massive amounts of interferon-gamma [39]. NK and CD8 T cells with degranulation defects have prolonged contact with the target cells, which can cause a fivefold increased release of interferon-gamma and promote hypercytokinemia [44]. All aspects of this immune dysfunction lead to signs and symptoms of $\mathrm{HLH}$, including hyperferritinemia, increased soluble IL-2 receptor (sIL2R), cytopenias, splenomegaly, hemophagocytosis, hypertriglyceridemia, fever, and hypofibrinogenemia [5].

\section{Secondary HLH}

sHLH patients have the same HLH phenotype as those with fHLH, but they lack the known HLH-associated genetic mutations. Secondary HLH can be induced by infection, rheumatologic disease, or malignancy. Infection-associated HLH can be due to viral, bacterial, fungal, or parasitic infection [45]. The most common viral culprits are the DNA viruses, including EBV, HHV6, parvovirus, HSV, CMV, and adenovirus [45]. HLH secondary to influenza and HIV (typically with superinfection) has also been described. Bacterial-associated HLH has been described particularly with Mycobacterium, as well as Staphylococcus aureus, Ehrlichia, Rickettsia, and Mycoplasma [45]. Parasitic infections are a common cause of HLH in countries outside of the United States, and causative agents include Leishmania (particularly visceral leishmaniasis), Plasmodium, and Toxoplasma. Histoplasmosis (particularly disseminated), Candida, and Cryptococcus are fungal agents that have been associated with HLH in the literature [33, 45].

$\mathrm{HLH}$-like presentation associated with rheumatologic disease is typically referred to as MAS or MAS-HLH. The rheumatologic disease most commonly associated with MAS is sJIA [46]. Up to 10\% of sJIA patients develop overt MAS, but there is evidence that up to $30 \%$ of patients may have subclinical MAS [47]. In addition, MAS has been described in SLE, adult-onset Still's disease, dermatomyositis, Kawasaki's disease, rheumatoid arthritis, and inflammatory bowel disease [46]. Malignancy-associated HLH is more commonly seen in adult patients but can also be seen in pediatric patients. It is most often associated with lymphomas, particularly $\mathrm{T}$ cell or NK cell, or leukemias [48]. It is thought that HLH may manifest due to 
immune dysregulation from dysfunctional leukemic or lymphoma cells with ensuing hypercytokinemia. Often there is a concomitant viral infection, particularly EBV $[33,48]$. In addition to HLH resulting directly from the malignancy, there are reports of HLH resulting after bone marrow transplant [49, 50], as well as malignancyrelated therapies including chemotherapy and immunomodulation [33, 48]. The majority $(88 \%)$ of patients that develop HLH related to cancer-directed therapy often have a concomitant infection, so infectious disease work-up is important in these patients [48].

The pathophysiology for secondary HLH is not as well understood as fHLH. Unlike the pathophysiology of primary HLH, secondary HLH pathophysiology cannot be completely explained by a defect in cytotoxic function, as many secondary HLH patients have normal NK-cell cytotoxic function when tested [10, 51]. Cytotoxic dysfunction and the sizable innate immune activation appear to work in concert leading to the subsequent cytokine storm and phenotype of HLH. It also appears that depending on the etiology of the secondary HLH, the predominance of innate immune system activation versus cytotoxic cell dysfunction may vary. The cytotoxic dysfunction that may occur in secondary HLH can be due to a direct, but reversible, defect in cytotoxic function or a relative cytotoxic dysfunction due to decreased numbers of NK or CD8 T cells $[33,52]$. The acquired cytotoxic dysfunction is particularly important in certain viral infections, such as EBV, influenza, and HSV, where the cytotoxic dysfunction is virally induced [44, 53, 54]. Prolonged increased IL-6, which can be seen in infection but is particularly common in rheumatologic disorders, can also play a role in acquired cytotoxic dysfunction by decreasing perforin and granzyme B expression [55]. In addition to acquired defects in cytotoxicity, overactivation of the innate immune system also plays an important role in the development of HLH, particularly MAS and sepsis or bacterial-induced HLH. Both sepsis and MAS are characterized largely by innate immune system activation by Toll-like receptors (TLRs) as well as high levels of IL-6, which have been shown to amplify TLR signaling [56]. In a recent murine model, it was demonstrated that blatant HLH phenotype with hypercytokinemia could be produced by repeated stimulation of TLR9 [57]. Contrary to primary HLH murine models, this process does not appear to be dependent on CD8 T-cell activation or interferon-gamma secretion $[57,58]$. Based on multiple murine cytokine neutralization studies, there is no single cytokine that is responsible for driving HLH/ MAS pathophysiology [33, 43]. IL-1 family, IL-6, IL-10, IL-18, and INF-gamma all appear to play a role in the pathophysiology and the MAS/HLH phenotype [33, 43, $57,58]$. While the differences between primary and secondary HLH or MAS may seem esoteric, the differences in pathophysiology will be crucial in predicting the best novel therapies, such as cytokine neutralization, that will be the most effective.

\section{Evolving Understanding of Secondary HLH}

Traditionally, secondary HLH has referred to patients that have the phenotype of HLH, but do not have bi-allelic mutations in HLH-associated genes. The distinction between primary and secondary HLH has become more complex as we have 
learned that some secondary HLH patients also carry polymorphisms (of unknown significance) or mono-allelic mutations in HLH-associated genes, although it is controversial if the reported polymorphism cause disease [36, 59-63]. In addition to mutations or polymorphisms in HLH-associated genes, there have been mutations and other variants found in secondary HLH patients with whole-genome sequencing, including mutations in genes involved with microtubule organization, vesicle transport, NK-cell receptors, cytokine production and signaling, inflammasome activation, and TLR signaling [33, 64]. This is an interesting concept as it suggests that these variants or mono-allelic mutations could lead to a small decrease in cytotoxic function or other immunopathology that may predispose an individual to develop HLH with an infectious or rheumatologic trigger. This may be an explanation why some individuals are predisposed to the development of HLH with infection while others may not.

\section{HLH Versus Sepsis Pathophysiology}

Are sepsis and HLH really that different? There are many similarities, but there are some very important differences between the immune response in HLH compared to sepsis. The best understanding that we have about immune function during the initial phases of sepsis and an HLH flare is from genomic expression profiling within the pediatric population and serum cytokines from both adult and pediatric studies. According to genomic expression profiling in sepsis, there is initially a large activation of the innate immune system, likely due to DAMPs (damage-associated molecular patterns) and/or PAMPs (pathogen-associated molecular patterns), and then the cytokine storm [65]. In sepsis, there is an immediate downregulation of adaptive immunity, increased apoptosis particularly of $\mathrm{T}$ cells, as well as decreased antigen presentation over the ensuing days (due to IL-4 and IL-10) [65]. However, in a primary HLH flare, there is a similar downregulation in genes related to adaptive immunity but also a downregulation in innate immunity and proteins related to promoting apoptosis [66]. Contrary to serum cytokine profiles, in genomic expression profiling, both HLH and sepsis patients demonstrated upregulation of genes related to the same cytokines, including IL-6, IL-10, and IL-1 family [65, 66]. Serum cytokine levels in HLH patients usually show an overwhelming predominance of INF-gamma (consistent with overwhelming CD8 T-cell activation) and IL-10 (released in an attempt to control the immune response) [42, 67-69]. TNF-alpha and IL-6 are elevated within the HLH group, but not predominant [36, 42, 67-69]. In sepsis, IL-6 and IL-10 levels tend to predominate with some elevation of TNF-alpha [36, 68, 70, 71]. Interestingly in sepsis, a low INF-gamma is associated with a poorer prognosis [72], most likely a herald for overwhelming immune suppression and lack of T cells. In summary, both syndromes have a similar initial release of cytokines with subsequent cytokine storm with a paradoxical but needed early attempt to control the immune response with the downregulation of multiple genes related to adaptive immunity. 
In primary $\mathrm{HLH}$, this attempted downregulation of the immune system is ineffective due to the lack of cytotoxic function of NK and CD8 T cells to appropriately dampen activated immune cells resulting in continued, unrestricted immune system activation and cytokine release. In sepsis, the term for this reactive downregulation of the immune system has been coined compensatory downregulation syndrome (CDS) $[73,74]$. In sepsis, downregulation of the immune system can be adequate, over-exaggerated, or inadequate. If the CDS is adequate, then the infection is cleared and the immune system returns to homeostasis and the patient will slowly improve. If CDS is overexaggerated, then immunoparalysis (defined as TNF-alpha release $<200 \mathrm{pg} / \mathrm{ml}$ with ex vivo lipopolysaccharide stimulation or monocyte HLA-DR) can occur with inadequate clearance of initial infectious agent or new nosocomial infection with multi-organ dysfunction syndrome (MODS) and increased risk of mortality [74, 75]. Interestingly, there is another newly described phenotype of MODS/sepsis in the literature, MAS-like MODS or macrophage activation-like syndrome [76-81]. This entity is thought to be caused by inadequate downregulation of the immune system with continued inflammation. Unfortunately, there is no consistent definition of these patients. Some fulfill five of eight HLH diagnostic criteria or the H-score [80, 82], while other studies describe sepsis characterized by hyperferritinemia, hepatobiliary dysfunction, and DIC with or without cytopenias [36, 76, 78, 81, 83]. The leading hypothesis for the pathophysiology for this subgroup of sepsis is thought to be partly due to CDS. Due to sepsis-related CDS, there is thought to be a decreased overall number of NK cells and/or function leading to impaired pruning of activated immune cells, including antigen-presenting cells and macrophages, as well as overactivation of the innate immune system via TLRs. While the literature is still young, those with hyperferritinemic $(>1980 \mathrm{ng} / \mathrm{ml}$ or $>4420 \mathrm{ng} / \mathrm{ml}$ ) sepsis represent an at-risk group with high mortality (44-46\%) [78, 81]. These MAS-like MODS/sepsis patients may not fit all HLH criteria, but they may represent patients in the HLH spectrum of inflammation that may benefit from some amount of immunosuppression [78, 80, 82, 83]. Despite this growing evidence for MAS-like MODS/sepsis, much work still needs to be done including more clearly defining this phenotype of sepsis within the literature and determining best therapy.

In conclusion based on emerging data, there are many potential reasons why sepsis and HLH appear phenotypically the same, particularly at initial presentation. There is a growing body of evidence to suggest that the amount of inflammation seen in sepsis, HLH, and MAS is not dissimilar, but rather each entity is represented on a spectrum of inflammation.

\section{HLH Evaluation and Testing}

There are several tests (Table 9.4) that can be sent immediately with a quick turnaround that can assist in the diagnosis of HLH. This includes complete blood cell count, coagulation studies with fibrinogen, ferritin level, lactate dehydrogenase 
Table 9.4 Initial testing for diagnosis and suggested testing are listed in the table. Those indicated with an astericks $\left({ }^{*}\right)$ represent tests that often require specialized testing at a send-out lab with varying expected return times. NK cell function, CD25 level, CD107a mobilization, perforin expression, XIAP, and SAP expression usual takes 2 to 5 days for results to return. Time for HLH genetic testing often requires 4 to 6 weeks

Recommended laboratory and diagnostic studies for HLH

Initial testing

Complete blood count

Basic metabolic panel

LDH

Coagulation studies including fibrinogen

Albumin

Liver function panel

Ferritin

Soluble IL-2 receptor or CD25 level ${ }^{*}$

NK-cell function*

Bone marrow biopsy

Hemophagocytosis

Optional:

Abdominal ultrasound to determine hepatosplenomegaly if not palpable

Tests to consider in primary $H L H$

Lumbar puncture

CSF cell count

CSF protein level

MRI head with and without contrast

CD107a mobilization*

Perforin/granzyme B expression*

HLH genetic panel*

In males:

XIAP and SAP expression*

Tests for HLH monitoring

Ferritin

Soluble IL-2 receptor or CD25 level

Once to twice weekly

Once weekly

(LDH), albumin, bilirubin (total and direct), and liver function studies. Other tests that are helpful for HLH diagnosis include soluble IL-2 receptor level (also known as CD25) and NK-cell function; however, in most institutions these are send-out labs and do not have a quick turnaround time. Soluble IL-2 receptor level acts as a barometer for the amount of T-cell activation and can be helpful in the diagnosis of HLH and following disease activity. The use of NK-cell function for HLH diagnosis is more nuanced as many secondary HLH patients will have normal NK-cell function [10, 51]. In addition steroids can cause NK-cell dysfunction making the study invalid once patients have received steroids. NK-cell function can also be normal in primary HLH patients, so a normal NK-cell function result does not rule out primary HLH [10]. Soluble CD163 is a marker of scavenger macrophage activation and may aid in making the diagnosis along with other tests. Patients with sepsis or infectious 
mononucleosis could also show elevated sCD163 levels; however there is minimal overlap compared to the levels seen in patients with HLH [84]. Bone marrow biopsy for the evaluation of hemophagocytosis can be helpful for the diagnosis of HLH, particularly in patients where the cause of persistent cytopenias is unclear, specifically in the context of a possible HLH at malignancy diagnosis, chemotherapy-related HLH, or HLH in the setting of bone marrow transplant. The result of the bone marrow biopsy must be considered in the whole of the clinical picture and alone cannot prove or disprove the diagnosis of HLH. Primary HLH patients can have a normal bone marrow biopsy particularly early in their illness $[5,11]$. In addition, hemophagocytosis can be found in critically ill patients without HLH, and hemophagocytosis is not always seen in HLH patients [36, 85-87]. Because of these reasons, hemophagocytosis is considered neither a sensitive nor a specific finding to diagnose HLH, and HLH diagnosis should not solely depend on the finding of hemophagocytosis but rather the complete clinical picture [86]. DIC or coagulopathy does not necessarily preclude performing bone marrow biopsy as the risk of bleeding is low. In addition, there are two functional flow cytometry tests that determine perforin/granzyme B expression and CD107a mobilization that typically have a turnaround time of 2-5 days (Fig. 9.1) $[10,51]$. These tests have been found to be both sensitive and specific for predicting the presence of an HLH-associated gene mutation [10, 51]. There are two other flow cytometry tests, SAP and XIAP expression, which should be sent in male patients for work-up for possible X-linked lymphoproliferative disease. Please see Table 9.3 for expected results for NK-cell function, CD107a mobilization, and perforin expression for different HLH-associated mutations.

While primary or familial HLH is most commonly thought of in neonates or those under 1 year of age, many familial HLH patients may not present until later in life depending on the severity of their mutation (i.e., and thus the degree of cytotoxic dysfunction). Due to this reason, genetic testing should be considered in all pediatric patients to determine if they have germline mutations associated with fHLH, especially in patients less than 1 year of age, or if perforin/granzyme B, SAP, XIAP expression, or CD107a mobilization testing is abnormal. For HLH genetic testing, next-generation sequencing (NGS)-based assays are commercially available to test for the genetic syndromes responsible for abnormal T-cell and NK-cell cytotoxicity leading to HLH development [88]. These tests take several weeks to result and should be sent early in the work-up in cases of high clinical suspicion.

In addition to testing required for HLH diagnosis, there are some additional tests that are helpful in determining additional type of HLH-specific therapy required, as well as response to therapy. Most patients with high suspicion of HLH should have a baseline MRI head and lumbar puncture with CSF studies (CSF cell count and differential and CSF protein level) $[2,15,16]$. These studies should be performed even if patients have no neurologic findings, as CSF pleocytosis and MRI findings can be seen in patients that are asymptomatic $[14,16]$. Due to higher mortality and significant morbidity in patients with abnormal CSF at diagnosis, patients with neurologic symptoms, CSF pleocytosis, and/or MRI findings may require additional intrathecal therapy $[2,14,16,36]$. In addition to CSF studies, all patients need a full infectious work-up including blood cultures, common viral etiologies (EBV, CMV, 
hepatitis viruses, adenovirus, influenza), and possible fungal etiologies even if there is suspicion of primary HLH. Rheumatology may need to be consulted to assist in further investigation of a possible underlying rheumatologic disorder. Both ferritin and soluble IL-2 receptor can be followed weekly to twice weekly to monitor patients' progress on therapy $[2,30]$.

\section{Intensive Care Presentation and Management}

In addition to the early diagnosis of HLH, most of the ICU (intensive care unit) management for HLH patients hinges on anticipation of HLH-related multi-system organ failure and providing adequate supportive care while getting immunosuppressive therapies initiated in a timely fashion. Another key point of management is the understanding that the severity of disease can change drastically in a matter of hours (sometimes as little as 6-12 h). Given this factor, another important aspect for care of HLH/MAS patients is frequent reevaluation and communication with the oncology, immunology, and/or rheumatology teams, especially if there is worsening in the patient's status, to determine if another agent or additional doses of agents, such as steroids, etoposide, anakinra, alemtuzumab, or a novel therapy, need to be given.

ICU care is centered around the management of quickly evolving multi-system organ failure, including cardiovascular, renal, hepatobiliary, neurological, respiratory, and hematological systems, including cytopenias and coagulopathy [89]. Reported reasons for ICU admission in the limited literature for HLH ICU patients (total of 80 patients described) include respiratory failure or ARDS (30-50\%), neurologic decompensation (encephalopathy, seizure; 20-21\%), shock or hypotension (18-22\%), acute renal failure (16\%), fulminant liver failure (7-30\%), and bleeding (5\%; Table 9.5) [90-92]. HLH patients had failure of two or greater organs at ICU admission [90, 92]. There were $44 \%$ of patients that were not diagnosed with HLH prior to ICU admission [90], which highlights the need for intensivists to have a low threshold for ruling out this diagnosis in the ICU particularly in patients with quickly decompensating MODS. These patients typically require multiple forms of interventional support including mechanical ventilation (57-100\%), vasopressors (43-80\%), and renal replacement therapy (17-75\%; Table 9.5) [90-93]. ARDS was described in as many as $90 \%$ of the patients in one study [92]. In addition to respiratory failure secondary to parenchymal disease, respiratory failure can occur due to significant organomegaly with decreased thoracic compliance and respiratory impingement. As many as $90 \%$ have been reported to have hepatomegaly and $76 \%$ with splenomegaly $[2,90-92]$. In the pediatric cohort, many patients required aggressive respiratory and cardiac support. The use of the high-frequency oscillatory ventilation and/or inhaled nitric oxide was described in three patients $(20 \%)$ that required mechanical ventilation, and $22 \%$ of the cohort required three or more vasopressors [91]. While up to one third of the ICU patients described required renal replacement therapy, clinical indication for renal replacement therapy (i.e., fluid overload vs. acute renal failure vs. oliguria) was not described; however, these 
Table 9.5 This table describes the described causes of ICU admission as well as the extensive supportive measures that are often required

\begin{tabular}{l|l}
\hline Reasons for ICU admission & $30-50 \%$ \\
\hline Respiratory failure & $20-21 \%$ \\
\hline Encephalopathy or seizure & $18-22 \%$ \\
\hline Hypotension/shock & $16 \%$ \\
\hline Acute renal failure & $7-30 \%$ \\
\hline Fulminant liver failure & $5 \%$ \\
\hline Bleeding or coagulopathy & \multicolumn{2}{|l}{} \\
\hline ICU supportive care requirements & $43-88 \%$ \\
\hline Vasopressors & $57-100 \%$ \\
\hline Mechanical ventilation & $20 \%$ \\
\hline iNO and/or oscillator (pediatric) & $17-75 \%$ \\
\hline Renal replacement therapy & $\sim 8.5$ units of product (adult) \\
\hline Frequent blood product transfusions & $1-7$ transfusions (average pediatric) \\
\hline Packed red blood cells & $0-4.5$ transfusions (average pediatric) \\
\hline Fresh frozen plasma & $0-12.5$ transfusions (average pediatric) \\
\hline Platelets &
\end{tabular}

patients can have extremely low albumin levels (1.6-3.2), capillary leak, and edema secondary to the severity of cytokine storm $[2,92]$. Anecdotally, these patients often have severe fluid overload and may benefit from continuous renal replacement therapy. In addition, many critically ill HLH patients require support with multiple transfusions, particularly platelet (mean platelet count $48-61 \times 10^{9} / \mathrm{L}$ ) and FFP or cryoprecipitate transfusions (mean INR 1.4, mean PTT 57.3, mean fibrinogen 130 $157 \mathrm{mg} / \mathrm{dl}$ ) [90-92]. Anemia (mean hemoglobin 8.3-10 g/dl) can be present, but is not as severe or as prominent as thrombocytopenia [90-92]. In one study, patients required an average of 8.5 units of product per person [92]. In a pediatric study, nonsurvivors required more blood products than survivors with a mean of 7 packed red cell transfusions, 4.5 transfusions of FFP, and 12.5 transfusions of platelets [91]. Many of these patients will have some amount of liver dysfunction ranging from transaminitis (41\%) and hyperbilirubinemia (mean bilirubin $6.45 \mathrm{mg} / \mathrm{dl}$ ) to fulminant liver failure $(7-30 \%)$ [90, 92]. Exploration of possible infectious etiologies needs to be performed and infections aggressively treated. HLH ICU non-survivors had higher organ dysfunction and mortality indexes at ICU admission compared to survivors and more often required supportive therapies including mechanical ventilation, renal replacement therapy, inotropes, and transfusion [90, 91]. Average length of ICU stay is 5.7-8.5 days [90-92]. Despite aggressive supportive therapy, ICU mortality is high in this subset of patients ranging from 35\% to $70 \%$ [90-92].

If these supportive measures are ineffective, extracorporeal life support (ECLS) can be considered within this patient cohort. Initiation of ECLS may allow time for immunosuppressive therapies to be effective. A recent study evaluating the survival of pediatric HLH patients on ECLS showed a survival rate of only 30\% [94]. This is significantly lower than the general pediatric ECLS survival of 59\% but is comparable to other immunocompromised pediatric cohort survival $(31 \%)$ and neonatal 
cardiac and E-CPR (extracorporeal cardiopulmonary resuscitation) patients $(38 \%)$ [94]. Indication for ECLS included respiratory failure, cardiac failure, and E-CPR with $63 \%$ being placed on venoarterial ECLS [94]. Unfortunately, no clear risk factors could be identified for increased mortality (including age, sex, time of ventilation prior to cannulation, vasopressors, or nitric oxide use), but all of the patients that were placed on ECLS for cardiac failure or E-CPR died [94]. There was also no indication whether these patients were primary or secondary HLH [94]. Care should be taken when managing anticoagulation on the circuit as many of these patients have underlying coagulopathy (DIC; 17\%) and the most common complication reported was bleeding with $>50 \%$ of patients reported to have bleeding at the cannula site and $17 \%$ with pulmonary or intracranial hemorrhage [94]. Infection status should also be considered when evaluating for ECLS candidacy, particularly in primary HLH patients since viremia or fungal diseases are more likely to persist due to their underlying cytotoxic defect which can complicate their ECLS course. Other patients with secondary HLH with infection (influenza, tick-borne diseases) have successfully cleared infection on ECLS [95-98].

A unique consideration within this group of patients is the various neurologic symptoms that can manifest including seizure, encephalopathy, focal deficits, ataxia, generalized hypotonia or hypertonia, or meningismus [15, 16]. With new onset symptoms, CT scan can be helpful to rule out intracerebral hemorrhage or significant cerebral edema. An attempt to manage cerebral edema with hypertonic therapy can be considered, but this has not been studied within the HLH population. Neurosurgical consult should be considered with both hemorrhage and cerebral edema for possible surgical intervention since both are potentially reversible phenomena once immunosuppressive therapy is started. Early initiation of HLH therapy is imperative to prevent or decrease the severity of long-term neurological sequelae $[15,16]$. MRI and lumbar puncture should be obtained once the patient is stable.

\section{HLH-Directed Therapy}

Because of the diagnostic challenges and significant mortality associated with HLH, when there is a high degree of suspicion, treatment often needs to be started before all HLH-specific testing has resulted. Patients often develop disease characteristics over time, and the delay in diagnosis could make it too late to initiate therapy. Organ failure (high sequential organ failure score) has been associated with significantly increased mortality in adult patients admitted to the ICU [99]; therefore an early consultation of an HLH expert is of utmost importance.

In broad terms, the management of familial or primary HLH includes a shortterm approach in a critically ill child controlling over-inflammation, targeting activated immune cells, and treating infections and a long-term approach replacing the defective immune system through a hematopoietic cell transplant (HCT) in familial HLH or refractory secondary HLH. Etoposide, an epipodophyllotoxin, was first used in the 1980s for HLH therapy and has become a mainstay in familial HLH 
therapy [100]. The mechanism for use in HLH is thought to be due to its ability to reverse defective apoptosis and to target activated T cells which are a known important driving force for the development of primary HLH [101, 102]. Similarly, corticosteroids have been the mainstay of HLH therapy and have been successfully used in combination with vinblastine/etoposide/teniposide/antithymocyte globulin [33, 35-37] [21, 103-105]. In 1994, the Histiocyte Society implemented the first international protocol (HLH-94) to treat previously untreated children and adolescents ( $<16$ years of age) with primary and secondary HLH. [1, 106] Patients were treated with an 8-week regimen using the combination of dexamethasone $\left(10 \mathrm{mg} / \mathrm{m}^{2}\right.$ for the initial 2 weeks followed by a taper over 2 months), and etoposide $\left(150 \mathrm{mg} / \mathrm{m}^{2}\right.$ twice weekly for 2 weeks, followed by $150 \mathrm{mg} / \mathrm{m}^{2}$ once a week for 6 weeks), and cyclosporine (CSA) in a continuation phase, starting at week 9 (Fig. 9.2). Patients with CNS HLH received intrathecal methotrexate, and patients with familial HLH were bridged to HCT. A total of 249 patients received the therapy with a 5-year overall survival of 54\% (95\% CI: 48-60\%) [2]. Pre-HCT mortality was 29\% [2]. The HLH2004 protocol aimed to improve the pre-HCT morbidity and mortality seen in HLH94 trial by using CSA up front [25]. Additionally, prednisolone was given intrathecally to reduce the late neurological sequelae (19\%) seen in HLH-94 protocol. Between 2004 and 2011, a total of 369 children were enrolled. Overall survival was $61 \%(56-67 \%)$ in the entire cohort, but the pre-HCT mortality was non-different compared to HLH-94 (27\% vs. 19\%, $p=0.064$ ) [25]. Therefore, upfront CSA approach was deemed not necessary. It is important to note that both trials used dexamethasone as the corticosteroid of choice due to its higher concentration in CSF compared to prednisolone [107] and the poor prognosis associated with CNS HLH. Children with abnormal CSF studies were at higher risk of mortality and late neurological sequelae in HLH-94 study [14].

When patients are initially treated, they typically will show improvement/stabilization within the first $48 \mathrm{~h}$ after they receive their initial dose of dexamethasone and etoposide. However, if no improvement or worsening is noted after the first week on therapy, we would consider them refractory to frontline therapy.

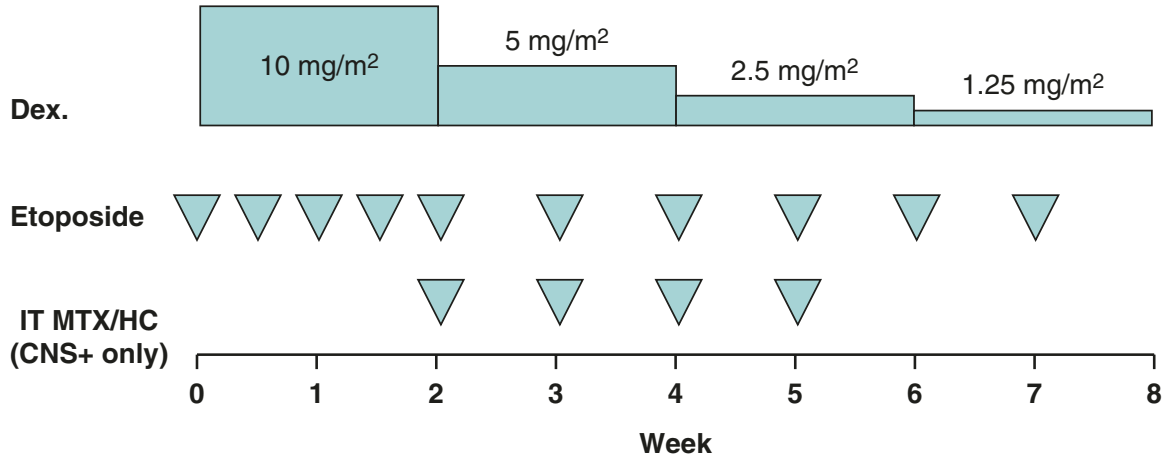

Fig. 9.2 Standard-of-care induction treatment for HLH (Dex. dexamethasone, etoposide dosing $150 \mathrm{mg} / \mathrm{m}^{2}$, IT MTX/HC, intrathecal methotrexate and hydrocortisone for patients with active CNS disease at week 2) 
Approximately $25-50 \%$ of patients will fail to achieve a complete response to the standard-of-care therapy or relapse and may require additional treatment with the same drugs or alternative "salvage" agents. Alemtuzumab, anakinra, and antithymocyte globulin have been reported in small studies as options for salvage therapy; however this has not been extensively studied [108, 109]. Future clinical trials are desperately needed in this patient population.

\section{Secondary/Acquired HLH}

Patients with secondary HLH in the ICU need prompt initiation of HLH-specific therapy regardless of the type of HLH (familial vs. acquired) [9, 110]. Often at diagnosis, it is impossible to distinguish between the primary and secondary HLH unless the patient has a known trigger, such as a malignancy or rheumatologic disorder. Efforts should be made to identify underlying trigger in patients with acquired or secondary HLH, especially infection and malignancy, which could be treated with appropriate antimicrobials or cancer-directed therapy, respectively. Decision for type and length of immunosuppression in this patient population must be made in consideration of patient's trajectory and severity of illness. There is a subset of patients with secondary HLH who will respond to steroids alone or in conjunction with IVIG that will have a good outcome without etoposide-based therapy. Decision to add etoposide is based on the severity of illness and clinical evolution and should be made early in the course, usually with a reassessment within 24-48 h after starting dexamethasone. Any worsening during a patient's clinical course should also trigger a reassessment for the addition of etoposide therapy. Additionally, in patients with EBV-associated HLH, the addition of rituximab (a CD20-specific antibody which targets B cells) to steroid or etoposide should be considered [111]. Those with chemotherapy-related HLH are a specialized group that require much careful consideration as further immunosuppression/ myelosuppression in an neutropenic patient with concurrent infection may not be therapeutic. In these patients, it is often prudent to hold chemotherapy and agressively treat the infection. It is often helpful for determining need for immunosuppresion in this group to obtain a bone marrow biopsy to determine if continued cytopenias are related to HLH or continued effect of previous chemotherapy [48].

Treatment of MAS is unique within the secondary HLH group. The mainstay of MAS therapy is high-dose pulse intravenous steroids with or without the addition of CSA or IVIG [112]. New cytokine inhibitors have shown promise in MAS and some secondary HLH patients. Anakinra, an interleukin-1 inhibitor, concurrently with steroids has been found to be helpful in the treatment of both MAS and MAS-like sepsis and is the most common biologic used for sJIA MAS therapy [82, 83, 112-114]. Similarly, tocilizumab (IL-6 inhibitor) has also shown durable responses in patients with adult-onset Still's disease [115]. While etoposide is not a mainstay of MAS therapy, if there is clinical deterioration or laboratory findings of worsening inflammation despite steroids, cyclosporine, or other disease-specific therapy, it is some- 
times necessary to escalate treatment to include etoposide or other HLH salvage therapy (such as ATG or Campath), or HCT.

\section{Novel Therapeutics}

Currently several novel agents are being studied for the management of HLH. Blockade of interferon-gamma (IFN $\gamma$ ) has shown therapeutic benefit in two models of perforinand Rab27a-deficient mice infected with lymphocytic choriomeningitis virus. Increased survival was noted in perforin-deficient mice, and resolution of cytopenias, reduction of cytokines, and hemophagocytosis were noted in both models $[39,116]$. Subsequently, NI-0501, a human anti-interferon-gamma monoclonal antibody (antiIFN $\gamma \mathrm{mAb}$ ), was used in a phase-2 trial setting including pediatric patients with primary HLH $(n=13)$ and showed a satisfactory response (69\%) [117]. Twelve patients received NI-0501 as a second-line agent, and 7 proceeded to allogeneic hematopoietic cell transplant. Resolution of CNS signs and symptoms was noticed in two evaluable patients. At 8-week follow-up, 11 patients were alive. Based on the promise shown in this trial, a multi-institutional clinical trial is currently studying the role of NI-0501 in pediatric patients with primary HLH (NCT01818492). Another ongoing clinical trial aims to study the safety and efficacy of anti-IFN $\gamma$ mAb in pediatric patients with systemic juvenile idiopathic arthritis developing MAS/secondary HLH (NCT03311854).

Ruxolitinib, a Janus kinase (JAK) 1/Janus kinase (JAK) 2 inhibitor, has been used as a therapeutic strategy in murine models of HLH. Ruxolitinib significantly improved cytopenias, organomegaly, and cytokinemia in murine models of HLH [118]. A trial is ongoing to study the effects of ruxolitinib in adults with secondary HLH (NCT02400463). It has also been used on an individual basis as a salvage therapy in pediatric and adult patients with HLH. Broglie et al. used it in an 11-year-old boy with HLH refractory to HLH-directed therapy and anakinra [119]. The patient was noted to have improvement in liver dysfunction, inflammatory markers, and resolution of fevers within $24 \mathrm{~h}$ of the medication administration. A critically ill adult patient with rheumatoid arthritis with secondary HLH responded within $48 \mathrm{~h}$ and survived [120]. Sin and colleagues published a case report describing the use of ruxolitinib in an adult patient with EBV-associated HLH [121]. The patient was also noted to have improvement in ferritin, $\mathrm{LDH}$, and liver function within 3 days, but bone marrow did not recover and patient had continued pancytopenia [121]. In the future, we anticipate potential use of newer less toxic pharmacologic options as first-line therapy options in critically ill patients who may not otherwise tolerate conventional chemotherapy.

\section{Conclusion and Future Directions}

The best care of HLH patients hinges on early recognition and initiation of immunosuppressive therapy as well as the aggressive supportive intensive care physicians are able to provide. Our understanding of HLH has evolved quickly over the 
last 30 years, but continued investigation of novel therapies will be imperative for further improvement in HLH patient outcomes.

\section{References}

1. Henter JI, Samuelsson-Horne A, Arico M, et al. Treatment of hemophagocytic lymphohistiocytosis with HLH-94 immunochemotherapy and bone marrow transplantation. Blood. 2002;100(7):2367-73.

2. Trottestam H, Horne A, Arico M, et al. Chemoimmunotherapy for hemophagocytic lymphohistiocytosis: long-term results of the HLH-94 treatment protocol. Blood. 2011;118(17):4577-84.

3. Henter JI, Horne A, Arico M, et al. HLH-2004: diagnostic and therapeutic guidelines for hemophagocytic lymphohistiocytosis. Pediatr Blood Cancer. 2007;48(2):124-31.

4. Henter JI, Elinder G, Soder O, Ost A. Incidence in Sweden and clinical features of familial hemophagocytic lymphohistiocytosis. Acta Paediatr Scand. 1991;80(4):428-35.

5. Janka GE. Familial and acquired hemophagocytic lymphohistiocytosis. Eur J Pediatr. 2007;166(2):95-109.

6. George MR. Hemophagocytic lymphohistiocytosis: review of etiologies and management. J Blood Med. 2014;5:69-86.

7. Allen CE, Yu X, Kozinetz CA, McClain KL. Highly elevated ferritin levels and the diagnosis of hemophagocytic lymphohistiocytosis. Pediatr Blood Cancer. 2008;50(6):1227-35.

8. Arico M, Janka G, Fischer A, et al. Hemophagocytic lymphohistiocytosis. Report of 122 children from the International Registry. FHL Study Group of the Histiocyte Society. Leukemia. 1996;10(2):197-203.

9. Jordan MB, Allen CE, Weitzman S, Filipovich AH, McClain KL. How I treat hemophagocytic lymphohistiocytosis. Blood. 2011;118(15):4041-52.

10. Rubin TS, Zhang K, Gifford C, Lane A, Bleesing JJ, Marsh RA. Perforin and CD107a testing are superior to NK cell function testing for screening patients for genetic HLH. Blood. 2017;129(22):2993-9.

11. Gupta A, Tyrrell P, Valani R, Benseler S, Weitzman S, Abdelhaleem M. The role of the initial bone marrow aspirate in the diagnosis of hemophagocytic lymphohistiocytosis. Pediatr Blood Cancer. 2008;51(3):402-4.

12. Stapp J, Wilkerson S, Stewart D, Coventry S, Mo JQ, Bove KE. Fulminant neonatal liver failure in siblings: probable congenital hemophagocytic lymphohistiocytosis. Pediatr Dev Pathol. 2006;9(3):239-44.

13. Henter JI, Nennesmo I. Neuropathologic findings and neurologic symptoms in twenty-three children with hemophagocytic lymphohistiocytosis. J Pediatr. 1997;130(3):358-65.

14. Horne A, Trottestam H, Aricò M, et al. Frequency and spectrum of central nervous system involvement in 193 children with haemophagocytic lymphohistiocytosis. $\mathrm{Br}$ J Haematol. 2008;140(3):327-35.

15. Horne A, Trottestam H, Arico M, et al. Frequency and spectrum of central nervous system involvement in 193 children with haemophagocytic lymphohistiocytosis. Br J Haematol. 2008;140(3):327-35.

16. Horne A, Wickstrom R, Jordan MB, et al. How to treat involvement of the central nervous system in hemophagocytic lymphohistiocytosis? Curr Treat Options Neurol. 2017;19(1):3.

17. Chong KW, Lee JH, Choong CT, et al. Hemophagocytic lymphohistiocytosis with isolated central nervous system reactivation and optic nerve involvement. J Child Neurol. 2012;27(10):1336-9.

18. Henter JI, Elinder G. Cerebromeningeal haemophagocytic lymphohistiocytosis. Lancet. 1992;339(8785):104-7.

19. Shinoda J, Murase S, Takenaka K, Sakai N. Isolated central nervous system hemophagocytic lymphohistiocytosis: case report. Neurosurgery. 2005;56(1):E187-90. 
20. Morrell DS, Pepping MA, Scott JP, Esterly NB, Drolet BA. Cutaneous manifestations of hemophagocytic lymphohistiocytosis. Arch Dermatol. 2002;138(9):1208-12.

21. Janka GE. Familial hemophagocytic lymphohistiocytosis. Eur J Pediatr. 1983;140(3):221-30.

22. Dhote R, Simon J, Papo T, et al. Reactive hemophagocytic syndrome in adult systemic disease: report of twenty-six cases and literature review. Arthritis Rheum. 2003;49(5):633-9.

23. Kaito K, Kobayashi M, Katayama T, et al. Prognostic factors of hemophagocytic syndrome in adults: analysis of 34 cases. Eur J Haematol. 1997;59(4):247-53.

24. Risdall RJ, Brunning RD, Hernandez JI, Gordon DH. Bacteria-associated hemophagocytic syndrome. Cancer. 1984;54(12):2968-72.

25. Bergsten E, Horne A, Arico M, et al. Confirmed efficacy of etoposide and dexamethasone in HLH treatment: long term results of the cooperative HLH-2004 study. Blood. 2017;130(25):2728-38.

26. Ouachee-Chardin M, Elie C, de Saint BG, et al. Hematopoietic stem cell transplantation in hemophagocytic lymphohistiocytosis: a single-center report of 48 patients. Pediatrics. 2006;117(4):e743-50.

27. Goransdotter Ericson K, Fadeel B, Nilsson-Ardnor S, et al. Spectrum of perforin gene mutations in familial hemophagocytic lymphohistiocytosis. Am J Hum Genet. 2001;68(3):590-7.

28. Molleran Lee S, Villanueva J, Sumegi J, et al. Characterisation of diverse PRF1 mutations leading to decreased natural killer cell activity in North American families with haemophagocytic lymphohistiocytosis. J Med Genet. 2004;41(2):137-44.

29. Stepp SE, Dufourcq-Lagelouse R, Le Deist F, et al. Perforin gene defects in familial hemophagocytic lymphohistiocytosis. Science. 1999;286(5446):1957-9.

30. Egeler RM, Shapiro R, Loechelt B, Filipovich A. Characteristic immune abnormalities in hemophagocytic lymphohistiocytosis. J Pediatr Hematol Oncol. 1996;18(4):340-5.

31. Schneider EM, Lorenz I, Muller-Rosenberger M, Steinbach G, Kron M, Janka-Schaub GE. Hemophagocytic lymphohistiocytosis is associated with deficiencies of cellular cytolysis but normal expression of transcripts relevant to killer-cell-induced apoptosis. Blood. 2002;100(8):2891-8.

32. Brisse E, Wouters CH, Matthys P. Hemophagocytic lymphohistiocytosis (HLH): a heterogeneous spectrum of cytokine-driven immune disorders. Cytokine Growth Factor Rev. 2015;26(3):263-80.

33. Brisse E, Wouters $\mathrm{CH}$, Matthys P. Advances in the pathogenesis of primary and secondary haemophagocytic lymphohistiocytosis: differences and similarities. $\mathrm{Br} \mathrm{J}$ Haematol. 2016;174(2):203-17.

34. Hines M, Nichols KE. Going with the flow: perforin and CD107a in HLH. Blood. 2017;129(22):2954-5.

35. de Saint BG, Sepulveda FE, Maschalidi S, Fischer A. Cytotoxic granule secretion by lymphocytes and its link to immune homeostasis. F1000Res. 2015;4(F1000 Faculty Rev):930.

36. Abdalgani M, Filipovich AH, Choo S, et al. Accuracy of flow cytometric perforin screening for detecting patients with FHL due to PRF1 mutations. Blood. 2015;126(15):1858-60.

37. Pachlopnik Schmid J, Canioni D, Moshous D, et al. Clinical similarities and differences of patients with X-linked lymphoproliferative syndrome type 1 (XLP-1/SAP deficiency) versus type 2 (XLP-2/XIAP deficiency). Blood. 2011;117(5):1522-9.

38. Sumegi J, Seemayer TA, Huang D, et al. A spectrum of mutations in SH2D1A that causes $\mathrm{X}$-linked lymphoproliferative disease and other Epstein-Barr virus-associated illnesses. Leuk Lymphoma. 2002;43(6):1189-201.

39. Jordan MB, Hildeman D, Kappler J, Marrack P. An animal model of hemophagocytic lymphohistiocytosis (HLH): CD8+ T cells and interferon gamma are essential for the disorder. Blood. 2004;104(3):735-43.

40. Terrell CE, Jordan MB. Perforin deficiency impairs a critical immunoregulatory loop involving murine CD8(+) T cells and dendritic cells. Blood. 2013;121(26):5184-91.

41. Lykens JE, Terrell CE, Zoller EE, Risma K, Jordan MB. Perforin is a critical physiologic regulator of T-cell activation. Blood. 2011;118(3):618-26. 
42. Henter JI, Elinder G, Soder O, Hansson M, Andersson B, Andersson U. Hypercytokinemia in familial hemophagocytic lymphohistiocytosis. Blood. 1991;78(11):2918-22.

43. Behrens EM, Koretzky GA. Review: cytokine storm syndrome: looking toward the precision medicine era. Arthritis Rheumatol. 2017;69(6):1135-43.

44. Jenkins MR, Rudd-Schmidt JA, Lopez JA, et al. Failed CTL/NK cell killing and cytokine hypersecretion are directly linked through prolonged synapse time. J Exp Med. 2015;212(3):307-17.

45. Rouphael NG, Talati NJ, Vaughan C, Cunningham K, Moreira R, Gould C. Infections associated with haemophagocytic syndrome. Lancet Infect Dis. 2007;7(12):814-22.

46. Atteritano M, David A, Bagnato G, et al. Haemophagocytic syndrome in rheumatic patients. A systematic review. Eur Rev Med Pharmacol Sci. 2012;16(10):1414-24.

47. Behrens EM, Beukelman T, Paessler M, Cron RQ. Occult macrophage activation syndrome in patients with systemic juvenile idiopathic arthritis. J Rheumatol. 2007;34(5):1133-8.

48. Lehmberg K, Sprekels B, Nichols KE, et al. Malignancy-associated haemophagocytic lymphohistiocytosis in children and adolescents. Br J Haematol. 2015;170(4):539-49.

49. Abdelkefi A, Ben Jamil W, Torjman L, et al. Hemophagocytic syndrome after hematopoietic stem cell transplantation: a prospective observational study. Int J Hematol. 2009;89(3):368-73.

50. Takagi S, Masuoka K, Uchida N, et al. High incidence of haemophagocytic syndrome following umbilical cord blood transplantation for adults. Br J Haematol. 2009;147(4):543-53.

51. Bryceson YT, Pende D, Maul-Pavicic A, et al. A prospective evaluation of degranulation assays in the rapid diagnosis of familial hemophagocytic syndromes. Blood. 2012;119(12):2754-63.

52. Grom AA, Villanueva J, Lee S, Goldmuntz EA, Passo MH, Filipovich A. Natural killer cell dysfunction in patients with systemic-onset juvenile rheumatoid arthritis and macrophage activation syndrome. J Pediatr. 2003;142(3):292-6.

53. Chuang HC, Lay JD, Hsieh WC, et al. Epstein-Barr virus LMP1 inhibits the expression of SAP gene and upregulates Th1 cytokines in the pathogenesis of hemophagocytic syndrome. Blood. 2005;106(9):3090-6.

54. Mao $\mathrm{H}, \mathrm{Tu} \mathrm{W}$, Qin $\mathrm{G}$, et al. Influenza virus directly infects human natural killer cells and induces cell apoptosis. J Virol. 2009;83(18):9215-22.

55. Cifaldi L, Prencipe G, Caiello I, et al. Inhibition of natural killer cell cytotoxicity by interleukin-6: implications for the pathogenesis of macrophage activation syndrome. Arthritis Rheumatol. 2015;67(11):3037-46.

56. Strippoli R, Carvello F, Scianaro R, et al. Amplification of the response to toll-like receptor ligands by prolonged exposure to interleukin- 6 in mice: implication for the pathogenesis of macrophage activation syndrome. Arthritis Rheum. 2012;64(5):1680-8.

57. Behrens EM, Canna SW, Slade K, et al. Repeated TLR9 stimulation results in macrophage activation syndrome-like disease in mice. J Clin Invest. 2011;121(6):2264-77.

58. Canna SW, Wrobel J, Chu N, Kreiger PA, Paessler M, Behrens EM. Interferon-gamma mediates anemia but is dispensable for fulminant toll-like receptor 9-induced macrophage activation syndrome and hemophagocytosis in mice. Arthritis Rheum. 2013;65(7):1764-75.

59. Wang Y, Wang Z, Zhang J, et al. Genetic features of late onset primary hemophagocytic lymphohistiocytosis in adolescence or adulthood. PLoS One. 2014;9(9):e107386.

60. Zhang K, Biroschak J, Glass DN, et al. Macrophage activation syndrome in patients with systemic juvenile idiopathic arthritis is associated with MUNC13-4 polymorphisms. Arthritis Rheum. 2008;58(9):2892-6.

61. Zhang K, Jordan MB, Marsh RA, et al. Hypomorphic mutations in PRF1, MUNC13-4, and STXBP2 are associated with adult-onset familial HLH. Blood. 2011;118(22):5794-8.

62. Zhang M, Behrens EM, Atkinson TP, Shakoory B, Grom AA, Cron RQ. Genetic defects in cytolysis in macrophage activation syndrome. Curr Rheumatol Rep. 2014;16(9):439. 
63. Zhang M, Bracaglia C, Prencipe G, et al. A heterozygous RAB27A mutation associated with delayed cytolytic granule polarization and hemophagocytic lymphohistiocytosis. J Immunol. 2016;196(6):2492-503.

64. Kaufman KM, Linghu B, Szustakowski JD, et al. Whole-exome sequencing reveals overlap between macrophage activation syndrome in systemic juvenile idiopathic arthritis and familial hemophagocytic lymphohistiocytosis. Arthritis Rheumatol. 2014;66(12):3486-95.

65. Wong HR, Cvijanovich N, Allen GL, et al. Genomic expression profiling across the pediatric systemic inflammatory response syndrome, sepsis, and septic shock spectrum. Crit Care Med. 2009;37(5):1558-66.

66. Sumegi J, Barnes MG, Nestheide SV, et al. Gene expression profiling of peripheral blood mononuclear cells from children with active hemophagocytic lymphohistiocytosis. Blood. 2011;117(15):e151-60.

67. Tang Y, Xu X, Song H, et al. Early diagnostic and prognostic significance of a specific Th1/Th2 cytokine pattern in children with haemophagocytic syndrome. Br J Haematol. 2008;143(1):84-91.

68. Xu XJ, Tang YM, Song H, et al. Diagnostic accuracy of a specific cytokine pattern in hemophagocytic lymphohistiocytosis in children. J Pediatr. 2012;160(6):984-90. e981

69. Osugi Y, Hara J, Tagawa S, et al. Cytokine production regulating Th1 and Th2 cytokines in hemophagocytic lymphohistiocytosis. Blood. 1997;89(11):4100-3.

70. Damas P, Canivet JL, de Groote D, et al. Sepsis and serum cytokine concentrations. Crit Care Med. 1997;25(3):405-12.

71. Rau M, Schiller M, Krienke S, Heyder P, Lorenz H, Blank N. Clinical manifestations but not cytokine profiles differentiate adult-onset Still's disease and sepsis. J Rheumatol. 2010;37(11):2369-76.

72. Jekarl DW, Kim JY, Lee S, et al. Diagnosis and evaluation of severity of sepsis via the use of biomarkers and profiles of 13 cytokines: a multiplex analysis. Clin Chem Lab Med. 2015;53(4):575-81.

73. Bone RC. Sir Isaac Newton, sepsis, SIRS, and CARS. Crit Care Med. 1996;24(7):1125-8.

74. Hall MW, Knatz NL, Vetterly C, et al. Immunoparalysis and nosocomial infection in children with multiple organ dysfunction syndrome. Intensive Care Med. 2011;37(3):525-32.

75. Muszynski JA, Nofziger R, Greathouse K, et al. Early adaptive immune suppression in children with septic shock: a prospective observational study. Crit Care. 2014;18(4):R145.

76. Carcillo JA, Podd B, Aneja R, et al. Pathophysiology of pediatric multiple organ dysfunction syndrome. Pediatr Crit Care Med. 2017;18(3_suppl Suppl 1):S32-45.

77. Carcillo JA, Podd B, Simon DW. From febrile pancytopenia to hemophagocytic lymphohistiocytosis-associated organ dysfunction. Intensive Care Med. 2017;43(12):1853-5.

78. Carcillo JA, Sward K, Halstead ES, et al. A systemic inflammation mortality risk assessment contingency table for severe sepsis. Pediatr Crit Care Med. 2017;18(2):143-50.

79. Castillo L, Carcillo J. Secondary hemophagocytic lymphohistiocytosis and severe sepsis/ systemic inflammatory response syndrome/multiorgan dysfunction syndrome/macrophage activation syndrome share common intermediate phenotypes on a spectrum of inflammation. Pediatr Crit Care Med. 2009;10(3):387-92.

80. Demirkol D, Yildizdas D, Bayrakci B, et al. Hyperferritinemia in the critically ill child with secondary hemophagocytic lymphohistiocytosis/sepsis/multiple organ dysfunction syndrome/macrophage activation syndrome: what is the treatment? Crit Care. 2012;16(2):R52.

81. Kyriazopoulou E, Leventogiannis K, Norrby-Teglund A, et al. Macrophage activation-like syndrome: an immunological entity associated with rapid progression to death in sepsis. BMC Med. 2017;15(1):172.

82. Rajasekaran S, Kruse K, Kovey K, et al. Therapeutic role of anakinra, an interleukin-1 receptor antagonist, in the management of secondary hemophagocytic lymphohistiocytosis/sepsis/multiple organ dysfunction/macrophage activating syndrome in critically ill children*. Pediatr Crit Care Med. 2014;15(5):401-8.

83. Shakoory B, Carcillo JA, Chatham WW, et al. Interleukin-1 receptor blockade is associated with reduced mortality in sepsis patients with features of macrophage activation syndrome: reanalysis of a prior phase III trial. Crit Care Med. 2016;44(2):275-81. 
84. Schaer DJ, Schleiffenbaum B, Kurrer M, et al. Soluble hemoglobin-haptoglobin scavenger receptor CD163 as a lineage-specific marker in the reactive hemophagocytic syndrome. Eur J Haematol. 2005;74(1):6-10.

85. Francois B, Trimoreau F, Vignon P, Fixe P, Praloran V, Gastinne H. Thrombocytopenia in the sepsis syndrome: role of hemophagocytosis and macrophage colony-stimulating factor. Am J Med. 1997;103(2):114-20.

86. Gupta A, Weitzman S, Abdelhaleem M. The role of hemophagocytosis in bone marrow aspirates in the diagnosis of hemophagocytic lymphohistiocytosis. Pediatr Blood Cancer. 2008;50(2):192-4.

87. Strauss R, Neureiter D, Westenburger B, Wehler M, Kirchner T, Hahn EG. Multifactorial risk analysis of bone marrow histiocytic hyperplasia with hemophagocytosis in critically ill medical patients--a postmortem clinicopathologic analysis. Crit Care Med. 2004;32(6):1316-21.

88. Filipovich AH, Chandrakasan S. Pathogenesis of hemophagocytic lymphohistiocytosis. Hematol/Oncol Clin. 2015;29(5):895-902.

89. Creput C, Galicier L, Buyse S, Azoulay E. Understanding organ dysfunction in hemophagocytic lymphohistiocytosis. Intensive Care Med. 2008;34(7):1177-87.

90. Buyse S, Teixeira L, Galicier L, et al. Critical care management of patients with hemophagocytic lymphohistiocytosis. Intensive Care Med. 2010;36(10):1695-702.

91. Leow EH, Soh SY, Tan AM, Mok YH, Chan MY, Lee JH. Critically Ill children with hemophagocytic lymphohistiocytosis: a case series of 14 patients. J Pediatr Hematol Oncol. 2017;39(6):e303-6.

92. Rajagopala S, Singh N, Agarwal R, Gupta D, Das R. Severe hemophagocytic lymphohistiocytosis in adults-experience from an intensive care unit from North India. Indian J Crit Care Med. 2012;16(4):198-203.

93. Wohlfarth P, Agis $\mathrm{H}$, Gualdoni GA, et al. Interleukin 1 receptor antagonist anakinra, intravenous immunoglobulin, and corticosteroids in the management of critically Ill adult patients with hemophagocytic lymphohistiocytosis. J Intensive Care Med. 2017; https://doi. org/10.1177/0885066617711386.

94. Cashen K, Chu RL, Klein J, Rycus PT, Costello JM. Extracorporeal membrane oxygenation outcomes in children with hemophagocytic lymphohistiocytosis. Perfusion. 2017;32(2):151-6.

95. Cheng A, Williams F, Fortenberry J, Preissig C, Salinas S, Kamat P. Use of extracorporeal support in hemophagocytic lymphohistiocytosis secondary to ehrlichiosis. Pediatrics. 2016;138(4):e20154176.

96. Henter JI, Palmkvist-Kaijser K, Holzgraefe B, Bryceson YT, Palmer K. Cytotoxic therapy for severe swine flu A/H1N1. Lancet. 2010;376(9758):2116.

97. Saites VA, Hadler R, Gutsche JT, Laudanski K. Extracorporeal membrane oxygenation for hemophagocytic lymphohistiocytosis. Am J Case Rep. 2016;17:686-9.

98. Wu ET, Huang SC, Sun LC, Ko WJ. Reactive hemophagocytic syndrome treated with extracorporeal membrane oxygenation. Pediatr Int. 2008;50(5):706-8.

99. Barba T, Maucort-Boulch D, Iwaz J, et al. Hemophagocytic lymphohistiocytosis in intensive care unit: a 71-case strobe-compliant retrospective study. Medicine. 2015;94(51):e2318.

100. Ambruso DR, Hays T, Zwartjes WJ, Tubergen DG, Favara BE. Successful treatment of lymphohistiocytic reticulosis with phagocytosis with epipodophyllotoxin VP 16-213. Cancer. 1980;45(10):2516-20.

101. Fadeel B, Orrenius S, Henter JI. Induction of apoptosis and caspase activation in cells obtained from familial haemophagocytic lymphohistiocytosis patients. $\mathrm{Br} \mathrm{J}$ Haematol. 1999;106(2):406-15.

102. Johnson TS, Terrell CE, Millen SH, Katz JD, Hildeman DA, Jordan MB. Etoposide selectively ablates activated $\mathrm{T}$ cells to control the immunoregulatory disorder hemophagocytic lymphohistiocytosis. J Immunol. 2014;192(1):84-91.

103. Fischer A, Virelizier JL, Arenzana-Seisdedos F, Perez N, Nezelof C, Griscelli C. Treatment of four patients with erythrophagocytic lymphohistiocytosis by a combination of epipodophyllotoxin, steroids, intrathecal methotrexate, and cranial irradiation. Pediatrics. 1985;76(2):263-8. 
104. Henter J-I, Elinder G, Finkel Y, Söder O. Successful induction with chemotherapy including teniposide in familial erythrophagocytic lymphohistiocytosis. Lancet. 1986;328(8520):1402.

105. Mahlaoui N, Ouachee-Chardin M, de Saint BG, et al. Immunotherapy of familial hemophagocytic lymphohistiocytosis with antithymocyte globulins: a single-center retrospective report of 38 patients. Pediatrics. 2007;120(3):e622-8.

106. Henter JI, Aricò M, Egeler RM, et al. HLH-94: a treatment protocol for hemophagocytic lymphohistiocytosis. Pediatr Blood Cancer. 1997;28(5):342-7.

107. Balis FM, Lester CM, Chrousos GP, Heideman RL, Poplack DG. Differences in cerebrospinal fluid penetration of corticosteroids: possible relationship to the prevention of meningeal leukemia. J Clin Oncol. 1987;5(2):202-7.

108. Marsh RA, Jordan MB, Talano JA, et al. Salvage therapy for refractory hemophagocytic lymphohistiocytosis: a review of the published experience. Pediatr Blood Cancer. 2017;64(4). https://doi.org/10.1002/pbc26308.

109. Marsh RA, Allen CE, McClain KL, et al. Salvage therapy of refractory hemophagocytic lymphohistiocytosis with alemtuzumab. Pediatr Blood Cancer. 2013;60(1):101-9.

110. Haytoglu Z, Yazici N, Erbay A. Secondary hemophagocytic lymphohistiocytosis: do we really need chemotherapeutics for all patients? J Pediatr Hematol Oncol. 2017;39(2):e106-9.

111. Chellapandian D, Das R, Zelley K, et al. Treatment of Epstein Barr virus-induced haemophagocytic lymphohistiocytosis with rituximab-containing chemo-immunotherapeutic regimens. Br J Haematol. 2013;162(3):376-82.

112. Minoia F, Davi S, Horne A, et al. Clinical features, treatment, and outcome of macrophage activation syndrome complicating systemic juvenile idiopathic arthritis: a multinational, multicenter study of 362 patients. Arthritis Rheumatol. 2014;66(11):3160-9.

113. Behrens EM, Kreiger PA, Cherian S, Cron RQ. Interleukin 1 receptor antagonist to treat cytophagic histiocytic panniculitis with secondary hemophagocytic lymphohistiocytosis. J Rheumatol. 2006;33(10):2081-4.

114. Miettunen PM, Narendran A, Jayanthan A, Behrens EM, Cron RQ. Successful treatment of severe paediatric rheumatic disease-associated macrophage activation syndrome with interleukin-1 inhibition following conventional immunosuppressive therapy: case series with 12 patients. Rheumatology (Oxford). 2011;50(2):417-9.

115. Sakai R, Nagasawa H, Nishi E, et al. Successful treatment of adult-onset Still's disease with tocilizumab monotherapy: two case reports and literature review. Clin Rheumatol. 2012;31(3):569-74.

116. Pachlopnik Schmid J, Ho CH, Chretien F, et al. Neutralization of IFNgamma defeats haemophagocytosis in LCMV-infected perforin- and Rab27a-deficient mice. EMBO Mol Med. 2009;1(2):112-24.

117. Allen C, De Benedetti F, Grom AA, et al. A novel targeted approach to the treatment of hemophagocytic lymphohistiocytosis (HLH) with an anti-interferon gamma (IFN $\gamma$ ) monoclonal antibody (mAb), NI-0501: first results from a pilot phase 2 study in children with primary HLH. 2015.

118. Das R, Guan P, Sprague L, et al. Janus kinase inhibition lessens inflammation and ameliorates disease in murine models of hemophagocytic lymphohistiocytosis. Blood. 2016;127(13):1666-75.

119. Broglie L, Pommert L, Rao S, et al. Ruxolitinib for treatment of refractory hemophagocytic lymphohistiocytosis. Blood Adv. 2017;1(19):1533-6.

120. Slostad JPJ, Tefferi A. Ruxolitinib as first-line treatment in secondary hemophagocytic lymphohistiocytosis: a single patient experience. Am J Hematol. 2017;93(2):E47-9.

121. Sin JH, Zangardi ML. Ruxolitinib for secondary hemophagocytic lymphohistiocytosis: first case report. Hematol Oncol Stem Cell Ther. 2017. https://doi.org/10.1016/ jhemonc.2017.07.002. 